\title{
Greek Tragedy
}

IOANNISN. GRIGORIADIS

A NKARA-Hubris, Ate, and Nemesis are three minor Greek deities, mostly remembered today for their function in ancient Greek drama. Hubris symbolizes arrogance, and deviation from virtue. Ate refers to an act of folly, a direct consequence of bubris, which provokes the wrath of gods and precipitates their intervention. Nemesis is the retribution of divine justice-painful, but necessary to restore world balance and order. The ongoing, multifaceted crisis that has torn apart Greece's economy and society since October 2009 can also be approached through the lens of this tragic classical trio.

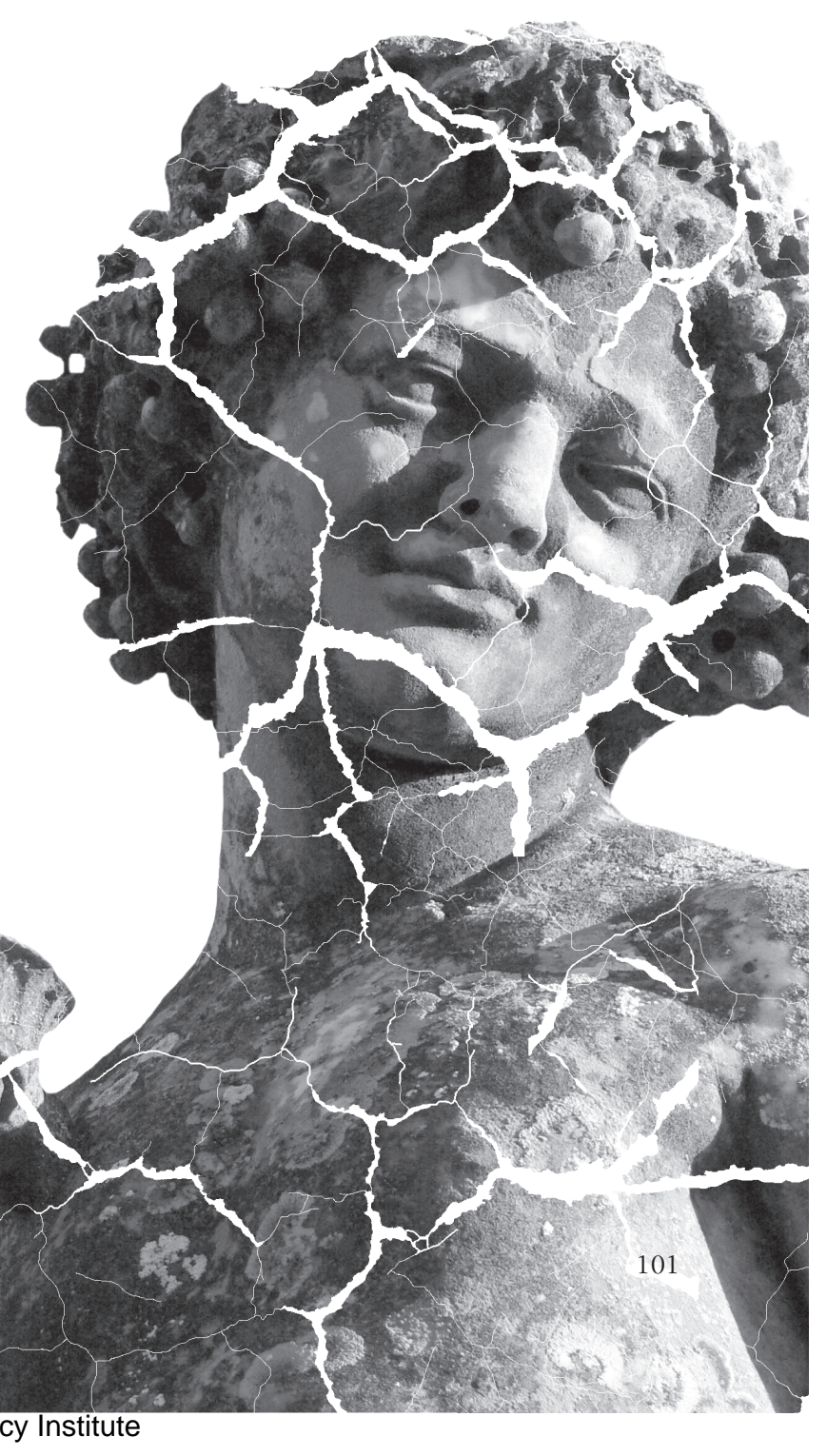


Today, the country is all but bankrupt, thanks in large part to excesses that have become endemic in Greek society and governance during the past three decades. Only the last-minute intervention of the European Union and the International Monetary Fund prevented a total meltdown of the country's economy in the spring of 2010. As a result, during the past 15 months, a new paradigm has been forced onto Greece. No longer can the profligacy of the past play any role in the country and its future. There is no other viable solution for Greece but radical reform.

This realization is the key moment of nemesis in today's Greek tragedy. It is also a reality that much of Europe is being forced to acknowledge. Ireland, Portugal, but also Spain, Italy and Britain-all are now confronting the costs of past excesses, their fiscal backs to the wall. If Greece can find a way to heal its self-inflicted economic wounds, it may offer a model for economic reinvention in Europe. If not, it may become a cautionary tale.

\section{THE ROOTS OF HUBRIS}

The contemporary Greek political elite bears a large burden of responsibility for the country's current woes. Yet the fundamental origins of Greece's problems can be traced to the era of Andreas Papandreou, a hero of the Greek left who served as the country's prime minister from 1981 through 1989, and again from 1993 until 1996. Before entering politics, Papandreou was a well-regarded economics professor in the United States, teaching at Harvard and the University of California at Berkeley. His father was Georgios Papandreou, a liberal former prime minister who died in 1968 after being placed under house arrest by the right-wing military junta that had taken power in Greece the previous year.

When the junta was overthrown in 1974, the younger Papandreou returned to Greece and formed a political party, the Panhellenic Socialist Movement (PASOK), which opposed Greece's entry into NATO and the European Economic Community (EEC). In 1981, Papandreou was elected Prime Minister, having campaigned on promises to withdraw Greece from those organizations and end the country's Cold War alignment with the United States. Once in office, Papandreou reneged on those promises, charting a more moderate course, at least when it came to foreign policy. Greece remained a full-albeit often problematic - member of the EEC and NATO.

Papandreou's leadership was instrumental in healing the wounds still festering from the 1946 to 1949 Civil War that pitted Greek against Greek-the conservative right and center versus the communist left. Exiled left-wing insurgents who left Greece in the aftermath of the Civil War were allowed to return, while their earlier contributions to the anti-Nazi resistance were officially recognized. Bureaucratic posts ceased to be a privilege offered exclusively to right-wing Greeks. But very rapidly, Papandreou's government began to go off the rails. Unprecedented levels of borrowing and spending created massive government debts. While debt-to-GDP ratio was 30 percent in 1980, it skyrocketed to 90 percent by 1990 .

The new funds were spent to subsidize private consumption rather than promote

loannis N. Grigoriadis, who was born and raised in Greece, is an assistant professor of political science at Bilkent University in Ankara, Turkey. 
development of infrastructure, which could have boosted growth. Salaries in the public sector kept rising, without generating any parallel growth in productivity. Economic assistance from the EEC increased the size of the pie without encouraging investment in long-term growth or fostering a culture of accountability. Under Papandreou, Greeks became accustomed to a perpetually improving standard of living. Yet it was financed not by genuine and sustainable economic growth, but by an ever-growing mountain of debt. Politicians who warned of the potentially disastrous consequences were repeatedly defeated in parliamentary elections and marginalized. At the same time, the state bureaucracy became infected by inefficiency, nepotism, and corruption.

Large swaths of the private sector, including the construction and telecommunications industries, became dependent on the state. Public health and education increased in scope but not in quality, and became tainted by rampant corruption. Pharmacists would bribe physicians to prescribe unnecessary drugs to their patients, paid for by the government. Public high school teachers would violate their oath of exclusive public service and earn extra money by offering private courses to students preparing for the university entry exam, depriving less-fortunate students of their attention in the classroom. As this kind of behavior spread, the social fabric was slowly shredding.

Official tolerance of corruption encouraged public acceptance of rule-breaking. Tax evasion became the norm, and honest taxpayers were often penalized by paying ever higher taxes on the income they voluntarily declared. Increasingly generous pensions and social benefits, combined with the country's aging population, undermined the stability of the Greek social security system.

Meanwhile, young Greeks became more interested in securing well-paid and undemanding government jobs, rather than improving their skills through education and seeking success through entrepreneurship.

These flaws remained fixtures of Greek society and governance long after Papandreou left office. Still, for nearly three decades, Greece escaped any real economic reckoning. It was aided by an exceptional amount of EEC/EU financial aid, in amounts that exceeded even those Greece received from the post-World War II Marshall Plan. These funds were disbursed with the aim of narrowing the gap between Greece and the more developed EU member states. Despite the inefficiency of the public sector, those funds did help improve

CRITICAL DEFICIENCIES OF THE GREEK STATE HAD BEEN CLEVERLY HIDDEN FROM VIEW FOR TOO LONG. the country's infrastructure. Greece's private sector also benefited from the post-Cold War opening of economies in the Balkans.

Throughout the 1990s, Greece's most competitive economic sector, shipping, took advantage of worldwide trade liberalization and steady growth in emerging markets like China, India, and Brazil. And between 1989 and 2000, the arrival of more than one million immigrants from southeastern Europe, the former Soviet Union, the Middle East, and the Indian subcontinent revitalized the Greek economy and gave a critical-if only temporary-boost to its competitiveness.

Spurred by those factors, the economic growth of the late 1990s allowed Greece's entry to the Eurozone and its adoption of the euro as its currency. Questions of fiscal reform, responsibility, and 
competitiveness were far from the minds of politicians and voters alike. The conviction that the country could indefinitely live beyond its means and enjoy a debtfinanced "Greek dream" was the defining moment of hubris.

\section{TWO MOMENTS OF ATE}

While Greece was pressing forward with its efforts to join the Eurozone in the late 1990s, it also embarked with great fanfare on a project that would most lucidly reveal its structural weaknesses and pave the way for a dramatic shift of fortunes-hosting the 2004 Olympics in Athens. The return of the Olympics to its ancestral home was greeted by the public with jubilation and pride. Still, there were a few skeptics who doubted the wisdom of the multi-billiondollar project. They were right.

The Athens games went smoothly. But the costs of hosting them far outweighed the benefits. Today, many buildings constructed for the Olympics remain under-used, even abandoned, since there was no comprehensive plan for their future after the games ended and the world departed. A rare opportunity to reshape Athens was squandered. Even worse, colossal cost overruns and astronomical budgets were financed through reckless borrowing. Estimates of the overall loss from the Olympics range from $\$ 15$ billion to $\$ 20$ billion. Yet it is hard to tell how much Greece lost, thanks to "creative accounting." (Several of the generous sponsorships that appeared as revenue, for example, originated in Greece's own public sector.) Far from restoring Olympic glory, the Athens games exposed critical deficiencies of the Greek state that had been cleverly hidden from view for too long.

Like the Olympics, Greece's entry into the Eurozone, in 2000, was initially cheered by both political leaders and voters. It was, indeed, a big national success. Yet the Greek government failed to make clear to the electorate that Eurozone membership came with strings attached. By voluntarily relinquishing national monetary policy, Greece could no longer periodically devalue its currency to increase competitiveness-a common practice for decades. Greek political elites continued to compete for the popular vote using the same old tricks, while European authorities failed to develop the supervision mechanisms that would ensure the accuracy of Greek financial statistics and the compliance of Greek economic policy with the Eurozone standards. In the absence of innovative policies to promote competition and reform, the prospects of the Greek economy remained bleaker than ever.

The left-leaning Papandreou era may have been the origin of contemporary Greece's hubris. But Greek governance truly hit its nadir during the 2004 to 2009 administration of Kostas Karamanlis, leader of the center-right New Democracy (ND) party. As the nephew of the conservative Prime Minister who had hauled Greece into the EEC in 1981, Karamanlis appeared to enjoy impeccable pro-market reform credentials and promised to reign in the out-of-control public sector. Yet his government was arguably the most profligate in recent Greek political history.

Low interest rates secured through Greece's Eurozone membership allowed the Karamanlis government to increase borrowing sharply in its efforts to support a growing and increasingly inefficient public sector. This proved to be a very popular and vote-winning policy. Salary and pension increases, subsidies, and tax rebates appeased powerful interest groups like farmers, trade unions, and civil servants. 
To disguise yawning current-account deficits and a steep rise of public debt, Greek statistical authorities employed creative accounting, circumventing or violating standard accounting practices in order to present a rosy picture of Greek state finances to the Eurozone authorities. To that end, special deals were made with Wall Street firms like Goldman Sachs. Debt obligations were masterfully packaged and concealed into complex financial instruments, so Greece could appear to be meeting its Eurozone deficit targets.

Meanwhile, corruption reached extraordinary proportions, even for the standards of a country with a rather poor record in public sector integrity. An anti-corruption investigation in Germany revealed that the electronics and engineering firm Siemens had bribed both major political parties and key ministers throughout the 1990s and early 2000s. A scandalous real estate deal between the government and a Mount Athos monastery proved to be the last straw. Despite public outrage, no political figures were prosecuted, owing to constitutional provisions guaranteeing a short statute of limitations and thus de facto impunity for MPs and ministers.

In the summer of 2007, a series of brush fires in the Peloponnese and other parts of southern Greece killed 80 people and reduced more than 1,000 square miles of forest and farmland-some three percent of Greece's territory-to ashes. This was by far the biggest natural disaster in Greece's recent history, and highlighted the inability of state officials to protect individuals and the environment. Still, Karamanlis was able to win re-election a few weeks later-thanks in part to a lavish, debt-financed compensation plan for those affected by the brush fires.

There was worse yet to come. In December 2008, following the killing of a young man by a policeman in Athens, riots wrought havoc on the center of the city. State buildings and shops were looted and set aflame, while the government and police stood by helplessly. Damage was estimated at $€ 200$ million or more. Downtown Athens appeared to be in a state of anarchy for several days for the first time since the end of World War II, when civil war had broken out. The stage was set for the final act.

\section{THE MOMENT OF NEMESIS}

As Warren Buffett once said, "It's only when the tide goes out that you learn who's been swimming naked." The global financial crisis that began in 2007 struck Greece at its most vulnerable and set the conditions for the moment of nemesis. Formerly abundant liquidity evaporated from global capital markets, exposing countries addicted to high levels of borrowing to unprecedented risks. Greece was at the head of the list.

In September 2009, Karamanlis announced that he would call early elections, due to the dire state of the economy and the need to take harsh, urgent measures. It turned out to be a politically suicidal move, and his party suffered the sharpest defeat of its almost 40-year history. PAsOK-now led by George Papandreou, son of Andreas-came to power with a comfortable parliamentary majority. Soon after, the new finance minister, George Papaconstantinou, announced a dramatic revision of the country's financial statistics. The current account deficit was revealed to be 13.6 percent of GDP, more than double the official figures of the now-defeated Karamanlis administration. The debt-toGDP ratio was also modified, from 103 percent to 125 percent - a high number, though far below, say, Japan. The difference was that Greece was uniquely combining a high public debt with a current account 
deficit and a severe competitiveness problem. It desperately needed global capital markets to finance this profligacy. And now, thanks to the worldwide financial crisis, the global windows were slamming shut.

Greek public debt was estimated to exceed $€ 300$ billion. Yields and spreads between Greek and German bonds reached all-time highs, and Greece rose to the top of the list of countries most likely to default. Government borrowing rates quickly became prohibitive. After some hesitation, Papandreou announced an unparalleled austerity program aimed at reducing the current account deficit to 2.5 percent within two years. Yet the global markets doubted the plan's feasibility. Given the country's imminent liquidity needs, the only way to avert a near-term bankruptcy was to seek international support. Despite his initial resistance, Papandreou announced on April 23, 2010, that his government had agreed to receive financial aid from the EU and the IMF.

The announcement failed to head off Standard \& Poor's decision four days later to downgrade Greek bonds to junk level. This was an extraordinary decision for a Eurozone member and a turning point for market sentiment, which effectively froze the Greek bond market. Fearing that an imminent default would lead to the country's exit from the Eurozone and the reintroduction of the drachma, many Greeks withdrew their bank deposits. They transferred their funds to "safe havens" such as Cyprus, Switzerland, or Britain, while others simply stored them in safe deposit boxes. Severe salary and pension cuts also led to recurrent strikes, demonstrations and social turmoil. Three clerks died when a bank branch was set aflame during a demonstration in the heart of Athens.
In May 2010, the IMF and the EU pledged $€ 110$ billion to help the Greek government refinance its deficit and debt without recourse to the financial markets, while the country enacted deep budget cuts and fiscal reforms. Additional aid was secured a week later, when the EU and the IMF agreed to an even more comprehensive plan. Some $€ 750$ billion was committed to the rescue of any Eurozone economy that might face financial difficulties. At the time, Greece was the only country with that level of need.

\section{TOUGH PLEDGES, HIGH PRICES}

Still, some tough pledges were the price for access to this enormous aid package. So the Papandreou government committed itself to the implementation of the most far-reaching economic and political reform program Greece had considered in decades. The terms of a memorandum signed between the lenders and the Greek government included promises to rationalize the country's social security system by raising the retirement age and slashing benefits, to remove numerous barriers to a free market (such as archaic "closed professions" rules that limited entry to a wide range of fields), to cut public sector salaries and benefits sharply, and to embark on an extensive privatization program of the telecommunication, energy and transport industries. Implementation of the memorandum's terms would be inspected periodically by the lenders and would serve as a condition for the delivery of the next loan tranche.

But there were further barriers to business as usual. For decades Greek politicians used to employ the devaluation weapon to deal with the consequences of imprudent economic policies. Yet things were different now. Since the country had forfeited this option when it entered the Eurozone, it now had to pursue a 
policy of "internal devaluation." In other words, competitiveness would be restored through the collapse of demand, the decrease of consumer prices, and reduced labor costs. Inevitably, this would prove to be a recipe for social turmoil.

In addition to its own self-inflicted structural and fiscal burdens, Greece had already fallen victim to growing economic uncertainty throughout the Eurozone, as well as speculation about the viability of the euro itself. Ten years after the introduction of the common European currency, the global economic crisis revealed some of the Eurozone's structural deficiencies. Greece has become the financially weakest member of the Eurozone and thus the most susceptible to the whims of capital markets. A Greek default would represent a major systemic risk, as several major European private financial institutions are heavily invested in Greek public debt and exposed to its credit-default swap market.

Nevertheless, despite the EU-IMF bailout and the commitment of the Greek government to the most comprehensive fiscal austerity and structural reform package in decades, markets remained skeptical about the feasibility of the rescue plan. While the bailout plan prevented the risk of an immediate Greek bankruptcy, it could not by itself address underlying reasons for the dire state of the Greek economy. Critics feared that the fiscal austerity plans would harm indiscriminately both the sound and corrupt sectors of the Greek economy and thus weaken the chances for a broad-based economic recovery.

A long debate has ensued over the question of how Greece will repay its debt under the terms set by the EU and IMF, without resorting to some sort of restructuring in the medium termfor example, an agreement by creditors to delay repayment terms or forgive some interest or principal on outstanding loans. One central reason is that the global capital markets that are Greece's creditors have priced in all the structural deficiencies they had ignored for so long. At the same time they promptly began questioning not only the willingness but also the ability of the Greek political elite to implement the promised reforms. Having deferred the resolution of deep fiscal and structural problems for nearly three decades, Papandreou's government appeared to be setting itself up for a nearterm failure. By April 2011, a year after the bailout was announced, it was clear that the Greek government would miss its target to reduce the current account deficit to 7.4 percent. Privatization revenues were far below the announced targets, while promised IT'S FAIR TO WONDER WHETHER TO TRUST A POLITICAL ELITE THAT IS THE PRODUCT OF A DYSFUNCTIONAL SYSTEM. deficit-cutting reforms in the public sector were still pending. It also appeared increasingly likely that Greece would be in need for further financing in 2012, in order to service its accumulated debt. An orderly and pre-agreed debt restructuring was called for, but that would require close cooperation between the Eurozone, the IMF and Greece.

An already-difficult situation was further complicated in May, when Dominique Strauss-Kahn resigned his post as managing director of the IMF after his arrest on charges of attempted rape in New York City. Strauss-Kahn had advocated 
decisive IMF action to avoid defaults in Greece and other debt-ridden Eurozone members, and his departure introduced yet another element of uncertainty into the picture. Just a week after StraussKahn's arrest, Greece announced it would speed up a plan to sell off $€ 50$ billion in state-owned assets over the next five years, including a state-owned bank and the country's two biggest ports.

\section{CULTURE SHOCK}

Implementing the demands of the EUIMF memorandum not only entailed painful economic sacrifices for the vast majority of the Greek people. It also implied a radical reconfiguration of the country's social, economic and bureaucratic model, which bore similarities to the transitions undertaken by the formerly communist states of central and eastern Europe in the aftermath of the Cold War two decades ago.

The challenges facing Papandreou go beyond the task of governing. What's called for is a transformation of Greek society-a sharp reduction in the size of the state, as well as its role in the economy; an end to the corrupt links between the state and large swaths of the nation's economic elite; reintroduction of an esprit de corps in a drastically reduced bureaucracy; a ruthless attack on an evergrowing shadow economy; and fostering a creative and entrepreneurial spirit among young people, through a reformed education system based on meritocracy. All of these steps will require courageous political leadership, able to withstand volatile popular reaction during the initial phases of the reform process. It's fair to wonder whether a political elite that is largely a product of this dysfunctional system can be trusted to promote measures that would eventually lead to its demise.
Yet the stakes are very high indeed. If this reform fails due to stiff social resistance and the IMF-EU memorandum is annulled, Greece may face a catastrophe of historic proportions that could threaten the political and economic accomplishments of six decades. At the political level, this could be translated into isolationism, nationalism and anti-Westernism. At the economic level, a cataclysmic depression could occur. An ever-growing number of skilled Greeks could face no other option but to emigrate. A brain drain that began at the onset of the crisis could assume dramatic proportions.

\section{THE MOMENT OF CATHARSIS}

According to Aristotle's classic definition, tragedy is "an imitation of an action that is serious, complete, and of a certain magnitude...with incidents arousing pity and fear, in order to accomplish a catharsis of such emotions." One cannot be certain about the timing of the catharsis in the ongoing Greek tragedy. The success of the Greek reform plan depends heavily on the determination of the current Greek government to stick with it. Most of the opposition parties - including the ND under its new leader, Antonis Samaras-have staked out populist positions that will make them unlikely to lend a helping hand.

Success also depends on the health of the global economy, and the Eurozone in particular. Even if the Greek government does everything right, a relapse of the global financial crisis or the outbreak of a major Eurozone crisis might suffice to derail its program.

It is too early to argue that the end of this Greek tragedy is in sight. Yet an outline of the key features of recovery is already clear. First, there is no way to talk seriously about economic recovery without addressing Greece's decades-long problem 
of tax evasion. This will require a radical revamping of the Greek tax-collection system, which is built around arcane legislation that leaves plenty of wiggle room for potential evaders. The government will have to create a highly skilled bureaucracy committed to the task of raising public revenues and the meticulous implementation of legislation. Tax evasion must cease to be a national sport and be treated for what it is-a crime.

Another indispensable step is a drastic reduction of the size of the public sector, which parasitically extracts resources from the rest of the economy. Indeed, whole sectors of the economy that escaped liberalization and privatization in the last decades will have to open up. This will make the distribution of the reform costs fairer and will also deprive cronyism of its natural habitat. A significant part of the Greek private sector has not been infected by the diseases of the public sector and remains the country's most important asset. It would be disastrous for the economy if the government implemented an austerity program that makes everyone poorer but fails to address the structural causes of the crisis-most importantly the size and the inefficiency of the public sector.

One factor working in Greece's favor is the cushioning effect of its EU and Eurozone memberships, a luxury not enjoyed by other countries that went through IMF interventions, such as Argentina. The systemic risk and disastrous political consequences that the default of a Eurozone member state would entail for the future of the European project would likely lead to a concerted European effort to prevent a Greek default. Still, it is not only the implementation but also the timing and execution of reforms that will have a central impact on how the rest of the world-and most importantly the financial markets—view the reform campaign.
To convince Greece's international debtors that a real shift has taken place, the government must provide a clear schedule for implementing changes — and maintain it.

Greece's path toward recovery will not only involve administrative reform. It also requires a major economic and cultural shift in people's lives. Greeks will have to give up living beyond their means and expecting every unfulfilled need to be met by the state. Wages, salaries, pensions, and lifestyles will have to be readjusted according to the real production capacities of the Greek economy, as well as the need to service the exorbitant debt. Greeks need to rid themselves of an infantile dependence on a "father-state" figure and take their responsibilities as citizens more seriously. The virtue of frugality needs to be introduced in the public and private spheres. This can only be accomplished if the political elite leads by example. A reduction of the size of the Greek parliament from 300 to 200 seats and a sharp cut of MP salaries are two symbolic steps that would underline the necessity of frugality for all.

Finally, the widespread culture of corruption and nepotism needs to be eradicated at all levels. Honest citizens can no longer be the losers. This may not be possible without a radical reconfiguration of the political system, including the replacement of the entrenched political parties with new parties that might more accurately reflect current sociopolitical trends.

Such a broad reformation could restore Greece's injured international profile and release political and social forces that could eventually realize the country's potential. Greece has a chance to become a model democracy and a successful Eurozone economy that could serve as a role model in southeastern Europe and the eastern Mediterranean. That would be the true catharsis of this modern Greek tragedy. 